\title{
Analysis of Workplace Surveillance in a Quest for an Ethical Stance
}

\author{
Saima Ahmed \\ University of Management and Technology, Pakistan
}

\begin{abstract}
This article examines the incidence of surveillance in higher learning academic institutions in Pakistan. It gives an overview of surveillance in a workplace and outlines how the latest technology has made the task more convenient for employers. It further delves into the privacy issues that arise as a consequence of surveillance. A review of related ethical theories has been undertaken to fathom the justification of surveillance practices in the modern workplace. In the literature review section, a number of studies that explore impacts of surveillance have been reviewed. The data has been gathered from 60 employees working in 5 different universities (both public and private sector) covering primarily their ethical stance on surveillance practices used. The study would help in figuring out the typical methods used and their extent of usage in order to establish incidence of surveillance in an academic institution setting. Finally, relevant hypothesis are tested with the available data to comprehend employees ethical stance on deployment of surveillance, their perception changes (if any) in case of availability of notices on surveillance etc.
\end{abstract}

\section{Keywords}

Workplace surveillance, higher learning academic institutions, Pakistan, ethical stance

\section{Introduction}

Institutions and business organizations generally use workplace surveillance as a way of monitoring the activities of their employees. In today's workplace, with the advent of latest technology, there has been an explosion of workplace surveillance. Employers that engage in surveillance practices do so for a variety of reasons such as to increase productivity, to review performances, to provide safe and secure working environment to the employees and also to protect company's vital assets against employees' misuse. Latest technology has now allowed employers to ask more of each employee simply because average productivity level has increased due to technology. It also provides us with a host of ethical challenges as new technology poses new implications for the balance of power in the workplace.

As long as there has been employment, employees have been monitored (Nebeker \& Tatum, 1993). The phenomenon of employers spying on their employees is not new. Henry Ford, for example, used to condition wages on workers' good behaviour outside the factory. It is said that he had 150 inspectors in

Copyright (C) 2007 Victoria University. This document has been published as part of the Journal of Business Systems, Governance and Ethics in both online and print formats. Educational and non-profit institutions are granted a nonexclusive licence to utilise this document in whole or in part for personal or classroom use without fee, provided that correct attribution and citation are made and this copyright statement is reproduced. Any other usage is prohibited without the express permission of the his sociological department to keep an eye on workers' hygiene and housekeeping habits.

In Pakistan, the extent of workplace monitoring and techniques deployed for monitoring purposes varies in different organizations. Usually, the incidence of monitoring is higher in the financial services 
sector such as banks, insurance, critical governmental agencies and pharmacies as here the employees are expected to be serving in sensitive positions. At the same time, most of the private sector organizations carry on surveillance practices on an occasional basis in the manner of spot checks rather than constantly or on a regular schedule. Furthermore, the distinction between personal and professional lives is getting indistinguishable in a modern workplace, as some employees conduct personal business in the office and professional business at home. It becomes evident that some work must be done at home in order to get accomplished on time, whereas, employees could get faster, cheaper and easier access to the Internet in their offices than their homes. The trend in Pakistan where both partners are working is also increasing gradually which commands additional personal calls from office to settle some family related issues. As no research has been found in Pakistan to address this issue, the present study is an attempt to facilitate research into surveillance and privacy in the workplace. It also aims to provide foundation for new analysis in future.

\section{Privacy in the Workplace}

The modern workplace has become the centre of the information society and privacy in the workplace has turned out to be a fundamental business issue of modern times. Joseph Kupfer (1987) defines privacy as "Privacy is the trusting way others treat us, resulting in a conception of ourselves as worth being trusted. In contrast monitoring behaviour and collecting data on us projects the disvaluing of the self in question".

Ethical issues when associated with privacy generally arise with gathering and disclosing of information and those related to information itself. Letting other people know your personal information is considered a privacy breach. It's a common human nature that people don't like other people knowing things about them immaterial to the fact with what they would actually do with that information.

Employers consider it as their right to manage the workplace, simply because they want to place workers in more suitable positions, they want to make certain productive performance and they also want to ensure fulfilment of positive actions. In order to accomplish all this, they consider it their right to know what their workers are doing in the workplace.

Employees, on the other hand, consider it their right to be treated as self-directed and capable individuals who can make their own decisions. They want to ensure their personal development and valued performance. They want to be treated as empowered individuals free from monitoring. They consider surveillance as their privacy breach.

\section{Use of Technology in Workplace Surveillance}

Use of technology for workplace surveillance purposes can be considered as one of the challenges of post modernism. The most modern surveillance tools allow employers to pin down the activities of their employees from web browsing to eavesdropping phone calls, from observing downloaded files to restricting access to various sites. Availability of products such as WebSense, New Access Manager, WebTrack and Internet Watchdog has made all this a lot more convenient. Also available is a truth telling device (from SpyShop.com) that once attached to a telephone could tell whether the individual on the other end of the line is speaking truth or telling a lie, and uses voice stress analysis to determine voice tremors for this purpose (Andrew Alderson, 1997).

Computer surveillance, also known as Employee Internet Management, is among the most popular form of workplace surveillance. This could be in the form of Internet surveillance, in which a special type of software can track of all of employees' activities on internet. Or it can in the form of Desktop surveillance in which the employer's computer by using specific surveillance software intercepts a signal that is given off by the employee's computer. Similarly, organizations use camera surveillance to thwart theft and vandalism. Security and legal personnel use these data to reduce legal responsibility, watch for the release of sensitive information, and curtail losses of company assets. 


\section{Literature Review}

Surveillance in the workplace has become an important issue facing both individuals and organizations in almost all over industrialized world. The literature review is essentially focused on the phenomenon of workplace surveillance, ethical issues that arise due to surveillance and its impact on the workforce. According to Botan (1996), the term monitoring refers to the collection of information about work regardless of purpose. Whereas surveillance, sometimes has a suspicious connotation associated with it because the information collected in this case has the potential to be used in a negative manner, such as restricting certain behaviours of the target individual/s. Also Nebeker and Tatum (1993) define electronic monitoring as "the use of electronic instruments or devices such as radio, video and computer systems to collect, store, analyse, and report individual or group actions or performance" (p. 509).

Researchers have carried out a number of studies to find out the impact of surveillance on various perspectives surrounding an employee's behaviour. Also, psychologists often quote the famous maxim that that "behaviour is a function of the person and the environment" by Kurt Lewin (1936). But first, a review of some ethical perspectives regarding privacy in the workplace follows:

\section{Workplace Surveillance: the Ethical Perspective}

As latest communication technologies are entering the workplace, so is the need for more detailed laws and regulations to clarify the rights of both the employee and employer (Botan, 1996). From an ethical standpoint researchers are concerned with the attack on employees' privacy and autonomy that electronic monitoring systems appear to represent (Hartman 2001). It is imperative that privacy issues in workplace should be dealt with some common understanding of ethics. The ethical debate also tries to find answer to the ethical justification on employee's right to privacy versus the employer's right to oversee the workplace. Whether employees have a right to privacy? Or is it the employer who has right to manage the workplace? Similarly, employers could now easily seek all kind of personal information on employees with the help of latest technology, but is this justifiable? To answer these and other similar questions one has to look into existing laws and ethical theories.

As new communication technologies are entering the workplace, the need for more specific laws and regulations to clarify the rights of both the employee and employer is getting more crucial (Botan, 1996). Take the case of email monitoring in Europe; for instance, in Germany, German Criminal Code Section 202a protects against access to encrypted e-mails. Employers wishing to monitor e-mails have to gain approval from the Works Council and individual employees. Similarly, France is also very restrictive in allowing employers to monitor e-mails. It is permissible only in cases justified to employee's task.

If we look at prevailing privacy laws in Pakistan, it becomes evident that constitution of Pakistan provides the basis for fundamental rights and guarantees the protection of life, liberty, body, reputation $\&$ property of an individual. Basic freedoms are dealt in articles $15,16,17,18 \& 19$. This constitution also states about security of person, i.e. "No person shall be deprived of life or liberty save in accordance with law."

The general law of contract in Pakistan is contained in the Contract Act 1872. The Act defines "contract" as an agreement enforceable by law. This act also defines frustration to occur in case of subsequent circumstances that the parties could not control and thus the agreement cannot be performed. However, it is not comprehensible whether surveillance can be considered to be part of "frustration".

Hence, it becomes evident that Pakistan's law does not yet provide an absolute answer to this. "While the law may offer protection in specific areas of our personal lives, it is incomplete - in part a result of the swift advance in technology, one that the law often has hard time capturing" (Steven Winters, 1993). Hence, a review on general ethical theories becomes crucial to get guidance in this case and this would also be helpful in consideration of rights. 
Philosopher John Locke has emphasized on protection of our natural rights. Hobbes on the other hand gave a somewhat pessimistic view by saying that human beings are capable of undertaking negative actions; therefore, a strong governmental (in this case organizational) hold is needed to provide security. Integrative Social Contracts Theory gives another relevant ethical viewpoint in this regard. By distinguishing between those values that are similar across cultures (hypernorms) and those that are culturally specific. This theory tries to verify the ethical principles that form the basis for hypernorms. This evidence could be established from international/national laws, religious principles, cultural recognition, and established industry standards. However, Integrated Social Contracts Theory is faced with certain limitations in practice. For example, the case where hypernorm-based employer's rights are debased by the hypernorms based protection of the employees' right or vice versa.

John Rawls, in his theory of distributive economic justice provides another pertinent point of view on ethical acts. Like Hobbes and Locke, Rawls too belongs to the social contract tradition. He defines ethical acts as those that lead to an equitable distribution of goods and services. In his theory, he poses a scenario that prevented people from knowing their status in a society so that they would decide about justice from behind a veil of ignorance. Without knowing what role people have to play in society, people would build a cooperative system that is perceptive to the welfare of all stakeholders. Rawls believes that the members of such system would not know whether they are among the employer population of employee population and therefore, actions undertaken in such a system are deemed ethical because of inherent fairness of the system. In short, this theory provides a sensible balance between economic and ethical consequences of privacy protection for both employees and employers.

Few ethical frameworks justify the act of monitoring in terms of its "utility to the organization" or its "consequences". Utilitarianism, however, is a very weak principle for ethical action. The fact that an act does not harm people does not mean it is ethical. Overall organizational goals can also be questioned against which policies are essentially providing utility to workers, for example, social and organizational justice requires that principles of distributive justice, equity, equality of opportunity could be used to evaluate systems for pay setting, recruitment and performance management etc. As far as consequentialism is concerned, justification of employer's monitoring is based on the fact that the prevailing law mostly held employer responsible for the act of employees, with this consequence in mind employers seek more and more information about prospective and currant employees to protect themselves from the tort "negligent Hiring" and vicarious liability (Robert Barker et al, 1995).

Laura P. Hartman (2001) suggests an approach based on two core values of integrity and accountability in order to balance interest of both employers and employees. Integrity, she says is consistency in values, and requires defining values and prioritizing them. This can be accomplished by an organization's mission statement. Following this, one may obtain direction from the mission statement. Assuming that monitoring does satisfy the organization's mission statement, the employer must implement monitoring in such a manner that is accountable to those affected by monitoring. Thus, accountability as suggested by Hartman means that the employer must value employees' privacy rights and let them make educated decisions about their dealings.

Only a few other empirical research studies have explored the surveillance from ethical perspective. For example, Greenberg (2002) has explored the influence of an ethics program on employee theft only. Greenberg has explored two related variables i.e. an ethics program and victim of theft. By ethics programs, he meant that the organization had a formal ethics program in place. The conclusions from this study were that employees stole less when they worked at an organization which had an ethics program in place and also stole less when they were told that the money came from individuals rather than the company.

\section{Justification of Workplace Surveillance}

Organizations might justify the use of surveillance in the workplace for various reasons. According to a survey conducted by the American Management Association (2000) the top most reported reasons for deploying surveillance included: acquiring information for performance reviews, guaranteeing legal 
compliance, and controlling costs. Other reasons included protection of business information, security, and safety (Daugherty, 1999; Howard, 1998). In countries like United States, American management association has conducted various surveys to find out the prevalence of electronic monitoring and surveillance deployed by business organizations in the country. However, statistics showing incidence of electronic monitoring in Pakistan are almost non existent.

\section{Impact of Surveillance}

This section of the paper reviews a number of academic studies that tackle surveillance from varying points of view i.e., both positive and negative outcomes of surveillance. Latest research shows that if someone questions you too much or takes away too much of your power, it may lead to insecurity, feeling of being overwhelmed and powerless. However, the variables that are considered to respond favourably in the presence of monitoring and surveillance are job performance and productivity. Motowidlo (2003) defines job performance as "the total expected value to the organization of the discrete behavioural episodes that an individual carries out over a standard period of time" (p. 39). In fact, it has become anecdotal that surveillance is the tool deployed by many employers to monitor the performance and productivity of their employees. Related studies from social psychology have measured the impact computer monitoring on job performance (Aiello \& Svec, 1993). Using the Social Facilitation Framework (Zajonc 1965), they explained the effects of electronic monitoring on job performance on simple and complex tasks with the hypothesis that the presence of another person increases performance on simple tasks and decreases the same on complex tasks. Aiello and Svec (1993) found a similar effect of computer monitoring. They concluded that if a job involves performing difficult tasks, it is more efficient not to have computer monitoring.

Another area of research interest on surveillance has been the impact of surveillance practices in the presence or absence of an advance notice in the form of organizational policies (Ambrose \& Alder, 2000; Bies, 1993). And also their impact on privacy perceptions held by employees. Ambrose and Alder (2000) have incorporated the variable 'disclosure of monitoring' in their studies. Bies (1993) states: "if I know in advance that I will be subjected to electronic monitoring or drug testing for example, I can take the necessary measures to be seen in a most favorable light". Another empirical study has found that employees are more accepting of drug testing programs and other HR practices involving personal information disclosure when advanced notice or agreement for disclosure is provided (Stone \& Kotch, 1989). Using a scenario study, Stone and Kotch (1989) found that employees were more accepting of a drug-testing program when advanced notice was provided.

In a field experiment conducted by Gary A. Ballinger (2002), the hypothesis: "Advanced notice of electronic monitoring (compared to post notice) will reduce invasion of privacy perceptions" was tested. The results predicted that post notice of monitoring would lead to significantly higher invasion of privacy perceptions respectively, compared to advance notice conditions. Thus, the hypothesis that advanced notice of electronic surveillance leads to lower invasion of privacy perceptions was fully supported in this experiment.

The conditions of advance notice as a critical component in employee acceptance of monitoring regimes in organizations has found considerable support in related studies (Ambrose \& Alder,2000), This effect is found in studies both within and outside of the performance monitoring arena (Stone \& Kotch, 1989, Alge, 2001).

Other researchers have investigated possible effects on the workforce such as stress (Aiello, 1993, Aiello and Kolb, 1995). Experiments conducted by Nebeker and Tatum (1993) to investigate the effects of computer monitoring, under different conditions of standards and rewards, on productivity, work quality, satisfaction and stress did not show any significant negative effects of computer monitoring. Botan \&Vorvoreanu, ( 2000) in their study claim that various discourses and interests interact in organizational settings, shaping the reality of being under electronic surveillance and influencing the extent to which the experience is negative and these issues were found to be absent in some related research conducted in experimental settings. The disciplinary dimension usually 
associated with surveillance in the real workplace was also absent. And they also isolated computer monitoring from other forms of surveillance. In a real work setting, there is much more at stake, which can increase the stress and other reported negative effects of electronic surveillance such as authority, control and other disciplinary actions.

The findings by Mason et al. (2002) have revealed that employees in their case studies appeared relatively unconcerned about privacy aspects of 'surveillance-capable technologies' in the workplace. Their case studies suggest that a more complex reality exists in the workplace and that the employees and their supervisors can collaborate to meet the organization's goals, whether this means using the monitoring/surveillance systems or finding ways to challenge them.

Botan \& Vorvoreanu (2000) in their investigation on whether monitoring leads to perceptions that work quantity is more important than quality, raised an important limitation of existing research is that it disregards employee voice i.e. surveillance does not usually consider the opinions of those who are surveilled. They also noted that a number of ethical issues related to electronic surveillance, such as perceptions of right and wrong in a real work setting are needed to be explored in detail.

\section{Methodology}

Addressing this limitation of existing research on absence of voice of those who are surveilled, the author is conducting this study. The paper would provide the basis for the methodology used to undertake the research which includes primary research using questionnaire to elicit stance of employees and their general perceptions on the incidence of surveillance. Keeping this notion in mind, the author in this study has specifically designed a questionnaire, to find out the viewpoints of those who are exposed to such surveillance technologies. This study will provide not only the statistics on surveillance techniques deployed, but also the employees' ethical stance and general viewpoint on the presence of such technologies in the modern workplace as the author found none of the research that summarizes these aspects in a Pakistani work environment. Also areas for further investigation will be highlighted.

In an attempt to stimulate further study of this topic the present study is limited to organizations in academic sector particularly the universities only. This empirical study essentially deals with finding out the predominant surveillance methods deployed by various degree awarding academic institutions in the city of Lahore, Pakistan. This study as opposed to some previous studies on similar topic is questionnaire based and data is gathered in real work setting. Gathering of employees' views in this manner is justified as personal' views speak about the person's values. A number of other researchers have based their studies on the similar findings from the classic structure of social psychology which states that values influence personality and personality influences the attitudes and that attitudes are directly related to behaviour. (Maloney and Ward, 1973; Kaiser et al., 1999). So similarly, this study aims to seek the views (telling about values) held by university's employees, their general attitude and their ethical stance towards workplace surveillance practices.

\section{The Hypothesis}

For the purpose of this research, the author has constructed a few pertinent hypotheses. The first hypothesis would figure out answer to the generic question, whether employees who are exposed to different surveillance techniques consider it ethically justifiable? Or do they believe in their own privacy and autonomy? So hypothesis is will be based on the assumption that employees perceive the presence of surveillance in modern workplace as unethical.

The second hypothesis is based on the assumption that the employees generally hold negative views on surveillance practices. Thirdly, it is hypothesized that the extent of surveillance is higher in private sector universities and institutions as compared to those serving in the public sector. 
Another hypothesis is set out to verify the notion that employees regard an advance notice about surveillance in the form of organization's policy, to be more acceptable than a post notice or secret surveillance and later questioning in case misbehaviour is detected.

\section{The Study}

The present study is undertaken to find out the ways in which surveillance-capable technologies are deployed by academic institutions in Pakistan, the purposes for which they are used and the views of the employees affected by them. This study aims to provide foundation for new analysis in future. The first part elicits statistics on the tools used for surveillance purposes. The remaining parts seek to test for the above mentioned hypothesis by analysing the feedback on carefully selected questions by those who are surveilled.

\section{Data}

In April-May 2007, a questionnaire was administered to employees working at various universities in the city of Lahore. Convenience sample was taken from employees working in both public and private sector universities as the exploratory nature of this relaxed the typical demands for representative sampling required in inferential research. A total of 75 questionnaires were administered in 6 universities in the city of Lahore only. Of which 60 responses were achieved giving us a response rate of about $80 \%$

The questionnaire comprised of 21 questions. The first part of questions elicits information on the different types of tools used for surveillance purpose. The second part asked for incorporation of surveillance related information in the institution's policy handout, how would the employees perceive the presence of surveillance related notices and how would they feel towards presence of secret surveillance method. The third part draws out information on the impact of surveillance, in this section, questions were carefully chosen from literature review findings and were intentionally worded with both positive and negative components in order to elicit a balanced appraisal rather than one focused only on problems or dissatisfaction. With this phrasing we anticipated to obtain a broad reflection on surveillance techniques used and to avoid prompting respondents with words representing the specific attitudes of interest. An open ended question was also included to get a profound insight on respondent's general outlook on workplace surveillance practices. And lastly, one final section on the questionnaire gathered information on respondent's profile and the type of organization he or she is serving for.

\section{Data Analysis}

After collecting data from 60 respondents serving in universities SPSS was used for analysis purposes. The data was tested both for its reliability and validity. Using Runs test, significant reliability was found for most of the key variables. For validity testing, Cronbach alpha value was calculated for the variables used in various tested hypothesis. These values are higher than 0.7 . Table 1.0 provides the summary of respondent's profile:

Table 1: Summary of Employee's Profile

\begin{tabular}{|l|l|l|l|l|l|}
\hline Designation & Percent & Age & Percent & Education Level & Percent \\
\hline Lecturer/TA/RA & 50 & $\mathbf{2 1 - 3 0}$ years & 45 & Masters & 61.7 \\
\hline Assistant Prof. & 15 & $\mathbf{3 1 - 4 0}$ & 30 & PhD & 8.3 \\
\hline Associate Prof./ Professor & 6.7 & $\mathbf{4 1 - 5 0}$ & 13.3 & Professional & 15 \\
\hline Other & 13.3 & $\mathbf{5 1 - 6 0}$ & 5 & Other & 8.3 \\
\hline
\end{tabular}

In one section of the questionnaire the information was gathered on the incidence of typical techniques deployed for surveillance purposes such as monitoring telephone usage, employee internet monitoring, video surveillance, review of email messages and mechanism for recording employee's work time. Half of the respondent's reported that their organization recorded the use of telephone by the employees. 
Presence of video cameras in universities was reported by only $36 \%$ of employees. As far as interception of email messages is concerned, $37.3 \%$ of respondent's affirmed the existence of mechanisms to intercept emails messages whereas $55.9 \%$ reported that there is no interception of emails and the remaining employers were not aware about the presence or absence of email interception. $60 \%$ of employees reported that their internet usage is monitored.

Lastly, employees were asked on the methods deployed by the organization to record their timings. In this case out of 60 responses received, nearly half reported on the absence of any mechanism by the organization to track their timings, 24 reported on time recording using a manual system such as signing the register and only 5 respondents revealed on the presence of an electronic time recording system to record their time. In the next part of the questionnaire, the employees were asked to rate their acceptability level both in case of presence of secret surveillance as well in case when an advance notice on the possible use of surveillance techniques is provided. These responses were measured using a 5 point Likert type scale $(1=$ Strongly acceptable, $5=$ Strongly Unacceptable). Cronbach alpha value in this case was found to be 0.798 and reliability was also significant.

As far as responses to an open ended question or the respondent's personal opinions on the institution of workplace are concerned, only 12 of the respondents fill up this section with their opinions. Four of the responses justified surveillance presence in an organization as it is required for smooth running, to protect resource misuse and to increase performance in an organization. Two of the respondents showed non favourable attitudes to surveillance as their responses vary from "against freedom" to "reduced creativity". Two respondents presented us with mixed feelings, one says that it is acceptable if incorporated to a reasonably and not excessively extent, whereas the other respondent mentioned of better ways to monitor productivity than mere surveillance. The remaining respondents reveal that the incidence of surveillance is normal for a workplace, it is good and that they are not much bothered about its presence.

\section{Results}

One sample t test was used to test for the hypothesis that employees perceive presence of workplace surveillance in universities as an unethical practice. The results in this case were found to be significant as this hypothesis was rejected. The results of $t$ test are shown in table 2.0.

Table 2: One Sample T Test

\begin{tabular}{|c|c|c|c|c|c|c|}
\hline & $\mathrm{T}$ & Df & $\begin{array}{l}\text { Sig. (2- } \\
\text { tailed) }\end{array}$ & $\begin{array}{l}\text { Mean } \\
\text { Difference }\end{array}$ & $\begin{array}{l}95 \% \mathrm{C} \\
\text { Interva } \\
\text { Differe }\end{array}$ & $\begin{array}{l}\text { fidence } \\
\text { f the } \\
\text { e }\end{array}$ \\
\hline & & & & & Lower & Upper \\
\hline Ethical Stance & -9.35 & 54 & 0.00 & -0.62 & -0.75 & -0.49 \\
\hline General Outlook & -11.015 & 56 & 0.00 & -0.68 & -0.81 & -0.56 \\
\hline $\begin{array}{l}\text { Perspective on surveillance } \\
\text { techniques used }\end{array}$ & -10.178 & 56 & 0.00 & -0.65 & -0.78 & -0.52 \\
\hline
\end{tabular}

Note: Test value $=2$ (For Ethical stance variable value 2 was used for Unethical. Similarly, 2 represent negative viewpoints in case of General Outlook and Perspective).

The data showed that out of 55 respondents who replied to this question 34 claim it as an ethically justified practice and 21 deem it as unethical.

For our second hypothesis concerning that employees generally hold negative views on the incidence of surveillance in an academic institute setting. This was tested by asking employees how they perceive the presence of surveillance as either it provides you with a feeling of being secured or with an intrusive feeling and whether your general outlook towards the deployment of surveillance techniques is positive or negative. The results were again found to be significant as this assumption was rejected at $5 \%$ level 
of significance. The results for this test are shown in Table 2. Cronbach alpha value for these related variables measured on similar scales is 0.7765 .

Table 3: Independent Samples Test

\begin{tabular}{|c|c|c|c|c|c|c|c|}
\hline & \multirow[t]{2}{*}{$\mathrm{F}$} & \multirow[t]{2}{*}{ Sig. } & \multirow[t]{2}{*}{$\mathrm{T}$} & \multirow[t]{2}{*}{$\mathrm{Df}$} & \multirow[t]{2}{*}{$\begin{array}{l}\text { Sig. } \\
(2- \\
\text { tailed }) \\
\end{array}$} & \multicolumn{2}{|c|}{$\begin{array}{l}\text { 95\% Confidence } \\
\text { Interval of the } \\
\text { Difference }\end{array}$} \\
\hline & & & & & & Lower & Upper \\
\hline Is Telephone Usage recorded & 1.399 & 0.242 & -1.653 & 58 & 0.104 & -0.5 & $4.74 \mathrm{E}-02$ \\
\hline Video Surveillance Present & 19.531 & 0 & -2 & 57 & 0.05 & -0.52 & $3.83 \mathrm{E}-04$ \\
\hline $\begin{array}{l}\text { Computer or Internet usage } \\
\text { Monitored }\end{array}$ & 1.213 & 0.275 & 0.518 & 56 & 0.607 & -0.2 & 0.35 \\
\hline Intercepting Emails & 0.294 & 0.59 & -0.047 & 57 & 0.963 & -0.34 & 0.32 \\
\hline Employee Time is recorded & 0.824 & 0.368 & 0.2 & 57 & 0.843 & -0.32 & 0.4 \\
\hline
\end{tabular}

Using Levene's test for equality of variances and $\mathrm{T}$ test for equality of means.

Table 3 shows $\mathrm{p}$ values for the hypothesis testing the notion that incidence of surveillance is lower in case of public sector universities. Equal incidence was assumed for the null hypothesis. The null hypothesis was fairly supported in case of technologies such as telephone usage recorded, computer or internet monitoring, intercepting of emails and recording of employee's time. However, the results were found to be significant ( 2 tailed) in case of video surveillance only. This 2 tailed $p$ value was converted into one sided test but the results were yet again significant.

For the hypothesis set out to verify the notion that employees regard an advance notice about surveillance in the form of organization's policy, to be more acceptable and hence ethically justified than presence of secret surveillance technique in a university. Regression using binary logistic analysis was performed to test this. Cox and Snell $\mathrm{R}$ square value was compared for both cases. The value of $\mathrm{R}$ square in case of an advance notice (Advance Notice: Cox and Snell R Square $=0.369$ ) was higher than the similar value calculated in presence of secret surveillance (Secret Surveillance: Cox and Snell R Square $=0.269$ ). However, these findings were not significant. Table 4 shows the frequency of employee's responses on various Likert scale items.

Table 4: Comparison of Surveillance Perceptions in Case of Presence vs. Absence of Advance Notices

\begin{tabular}{|l|l|l|l|l|l|}
\hline \multicolumn{2}{|l|}{ In case of advance notice on Surveillance } & \multicolumn{4}{l|}{ Presence of Secret Surveillance } \\
\hline & Frequency & Percent & & Frequency & Percent \\
\hline Strongly acceptable & 14 & 23.3 & Strongly Acceptable & 5 & 8.3 \\
\hline Somewhat acceptable & 27 & 45 & $\begin{array}{l}\text { Somewhat } \\
\text { Acceptable }\end{array}$ & 19 & 31.7 \\
\hline Indifferent & 13 & 21.7 & Indifferent & 21 & 35 \\
\hline Somewhat Unacceptable & 3 & 5 & $\begin{array}{l}\text { Somewhat } \\
\text { unacceptable }\end{array}$ & 11 & 18.3 \\
\hline Strongly unacceptable & 1 & 1.7 & Strongly against it & 2 & 3.3 \\
\hline
\end{tabular}

\section{Discussion}

From research point of view, surveillance has become an important topic today and its use in modern workplace has also pondered a number of ethical issues. In post modern era, with significant developments in technologies, the task of surveillance has become more convenient and less costly for the employers. This empirical study has been carried out essentially to explore incidence of surveillance and its ethical implications in universities in Pakistan.

In universities setup, the predominant technique used for surveillance was found to be in the form of computer monitoring or employee Internet management as $60 \%$ of employees reported its presence. This was followed by recording of telephone usage as this was reported by $50 \%$ of employees. 
Use of surveillance is generally considered as an invasion of individual privacy. Those who are against its usage perceive it as an unethical practice. Previous research efforts (e.g. Aiello \& Kolb, 1995) have led to a widespread belief that employees find surveillance to be invasive. Surprisingly, in case of universities in Pakistan, most of the employees perceive it as ethically justified as the author in this study fails to reject hypothesis perceiving it unethical. The study also revealed that majority of respondents hold positive opinions on the deployment of surveillance. The data showed that $62 \%$ of employees believe that surveillance provides them with security while only $33 \%$ perceive it as intrusive. Similarly $65 \%$ of employees have a positive outlook on surveillance while only $30 \%$ presented us with a negative outlook.

Another issue that this research explored was to confirm the previous findings that surveillance is more acceptable and justified in case employees are informed in advance (Ambrose and Alder, Stone and Kotch etc) by the university about their usage. The present study compares the acceptability perceptions of surveillance both in case of presence and absence of such notices. The regression analysis showed $\mathrm{R}$ square value to be higher in case the employees are informed in advance than the similar value calculated for that of secret surveillance. However, this could not be considered as significant finding. The summary of results showed that $70 \%$ of respondents consider it to be either strongly or somewhat acceptable in case a notice is provided whereas more than $60 \%$ of employees are either indifferent or they perceive secret surveillance as unacceptable. This indifferent attitude is comparable to the findings by Mason et al. (2002) that employees are generally indifferent to presence of surveillance practices.

\section{Conclusion}

In the post modern era, with the advent of some latest technologies it has become possible for organizations to continuously monitor activities of their employees, in ways more intrusive than was possible with conventional ways. And this failure to protect privacy ultimately leads to an inability to protect personal freedom and autonomy on an employees' part. Web browsing, personal use of office email, and/or making personal phone calls all account for spending company's time and resources on non-business related activities. From an ethical standpoint, the researchers had been trying to justify the employee's right to privacy versus the employer's right to control the work tasks. This study summarizes the incidence of surveillance technologies deployed in universities and would help them identify the general perception of employees towards surveillance practices.

The work provides evidence concerning the predominant tools used for surveillance purposes and the proportion of their usage in academic setting. Nonetheless, this study suggests that most employees in academic institutions of Pakistan do not perceive surveillance in the workplace as unethical or intrusive. Some respondents were actually found appreciating the surveillance presence by saying that it provides them with a feeling of being secured while at work. It also shows that acceptance of surveillance techniques would be greater if employees are informed in advance in the form of company's policies for the possible use of these devices. These findings further highlight the importance of explicit and wellcommunicated organizational policies for surveillance techniques communicated to the employers. Generally, the use of these tools seems to be well accepted. The survey findings are encouraging for the development of a more focused instrument helping to understand the consequences surveillance in the workplace.

\section{Limitations}

This research only considers employee perceptions on surveillance regardless of the perceptions of employers. The sampling strategy and sample size of the present study was not a probability sample, as a result, it may be prone to selection bias. These viewpoints might be more representative of faculty members of universities as equal allocation sample size was not used for various levels of employees. The proportions obtained in this study only give an indication to a larger population. 


\section{Future Research}

A great deal of research still remains to be done in Pakistani context to better understand the impact of surveillance on the workforce in general and its effect on performance and productivity in particular. A large-scale survey across multiple professions is needed to ascertain the proportions of employees that feel positively or negatively about workplace surveillance in Pakistan and also to seek whether there are difference of opinions among different demographic groups. Replicating this study with a more representative sample from other organizations such as financial institutions would be an important step. The research reported in this paper could also be extended to see if attitudes towards surveillance depend on particular type of surveillance method used. For instance, video surveillance may be preferred for providing high security reasons, whereas email interception may indicate lack of trust on organization's employees. Hopefully, future research will build on these and could also specifically examine negative impacts on workforce in Pakistani work environment.

\section{References}

Aiello, J.R., \& Svec, C.M. (1993), "Computer monitoring of work performance: Extending the social facilitation framework to electronic presence", Journal of Applied Social Psychology, 23(7), 537548.

Aiello, John R. \& Kolb, Kathryn J. (1995), "Electronic performance monitoring and social context: impact on productivity and stress". Journal or Applied Psychology, vol. 80 (no. 3), 339-353.

Aiello, John R. (1993), “Computer-based work monitoring: electronic surveillance and its effects". Journal of Applied Social Psychology, vol. 23 (no. 7), 499-507.

Alge, B.J. (2001), "Effects of computer surveillance on perceptions of privacy and procedural justice". Journal of Applied Psychology, 86: 797-804.

Alge, B.J., Ballinger, G.A. \& Smithson, H. (2001), “Internet surveillance: The effects of notification policies on privacy \& procedural justice". Paper presented at the Annual Meeting of the Academy of Management, Washington, DC.

Ambrose, M. L., \& Alder, G. S. (2000), "Designing, implementing, and utilizing computerized performance monitoring: Enhancing organizational justice". Research in Personnel and Human Resources Management, 18: 187-219.

Ballinger, Gary A. (2002) "Privacy and Procedural Justice Reactions to Internet Monitoring under Different Job/Roles and Task Deviance Conditions: A field experiment”, Purdue University, Submitted to the Organizational Behavior/Organizational Theory Track, $45^{\text {th }}$ Annual Meeting of the Midwest Academy of Management.

Bies, R. J. (1993), "Privacy and procedural justice in organizations". Social Justice in Research, 6: 6986.

Botan, C. H. (1995), "Electronic surveillance in the workplace: Predicting panoptic effects on employees". Paper presented to the Speech Communication Association Conference, El Paso, TX.

Botan, C. H., \& Vorvoreanu, M. (2000), "What Are You Really Saying To Me? Electronic Surveillance In The Work Place" Paper Presented to the Conference of the International Communication Assciation Conference, Acapulco, Mexico.

Daugherty, C. (1999), "Employers use high-tech tools to watch employees”. New Orleans City Business 19(27), 10-12.

Diana Winstanley, Jean Woodall, Edmund Heery, (1996), "Business Ethics And Human Resource Management", Themes and Issues, Personnel Review, Vol. 25, No. 6, pp. 5-12. ISSN 0048-3486.

Greenberg, J. (2002), "Who stole the money, and when? Individual and situational determinants of employee theft". Organizational Behavior and Human Decision processes, 89, 985-2003.

Hartman, Laura P. (2001), "Technology and ethics: privacy in the workplace". Business and Society Review, vol. 106 (no. 1), 1-27.

Howard, C. (1998), "Security banquet". Canadian Business, 71(13), 80.

Joseph Kupfer (1987), "Privacy, Autonomy and Self Concept", American Philosophical Quarterly 24, 81,82 
Kaiser, F., Ranney, M., Hartig, T. \& Bowler, P.A. (1999a), “Ecological environment”. European Psychologist, 4, 59-74.

Lewin, K. (1936), "Principles of topological psychology". New York: McGraw-Hill.

Magnusson, D. (Ed.). (1981), "Toward a psychology of situations: An interactional perspective". Hillsdale, NJ: Lawrence Erlbaum Associates, Inc

Maloney, M.P. \& Ward, M.P. (1973), "Ecology: let's hear from the people: An objective scale for the measurement of ecological attitudes and knowledge". American Psychologist, 28, 583-586.

Motowidlo, S. J. (2003), “Job performance”. In W. C. Borman, D. R. Ilgen, \& R. J. Klimoski (Eds.), Handbook of psychology: Vol. 12: Industrial and organizational psychology (pp. 39-53). NY: John Wiley.

Nebeker, D. M. and Tatum, B. C. (1993), "The effects of computer monitoring, standards and rewards on work performance, job satisfaction, and stress". Journal of Applied Social Psychology, 23, 508536.

Robert Barker and Alvin Hammond, (1995), "Legal Liability and Email”. Journal of System management 46, April 1995, 18.

Steven Winters, (1993), "The New Privacy Interest: Electronic Mail in the workplace”, 8: 1 High Technology Law Journal, 197-233.

Stone, D. L., \& Kotch, D. (1989), "Individuals' attitudes toward organizational drug testing policies and practices". Journal of Applied Psychology, 74: 518-521.

Zajonc, R.B.(1965), "Social Facilitation. Science", 149, 269-274. In Griffith, T.L. (1993). Monitoring and performance: A comparison of computer and supervisor monitoring. Journal of Applied Social Psychology.

\section{Web References:}

American Management Association (2000): "Electronic Monitoring and Surveillance, summary of key findings

Andrew Alderson, "Phone that Calls Foul on a Lie", The Sunday Times, $13^{\text {th }}$ July 1997, http://www.sunday-times.co.uk/cgi-bin/BackIssue? 2616834. 